\title{
The Relationship between Teacher-student Relationship and Academic Achievement: The Mediating Role of Self-efficacy
}

\author{
ZhuZhu Xu ${ }^{1}$, Chunxia Qi ${ }^{1 *}$ \\ ${ }^{1}$ Beijing Normal University, CHINA \\ Received 14 January 2019 - Revised 12 March 2019 - Accepted 13 March 2019
}

\begin{abstract}
This study investigated 42,643 eighth grade students from 762 secondary schools in 104 districts and counties in the $Z$ province of mainland China and also test the mediating role of self-efficacy in teacher-student relationship prediction of academic achievement. The results show that there are certain gender differences and regional differences in teacher-student relationship, but they have no practical significance; teacher-student relationship and self-efficacy can significantly predict mathematics academic achievement and both have a positive effect; self-efficacy plays an intermediary role between teacher-student relationship and mathematics achievement, and the ratio of the mediating effect to the total effect is $68 \%$.
\end{abstract}

Keywords: academic performance, mediating role, self-efficacy, teacher-student relationship

\section{INTRODUCTION}

In many studies, there is a certain reciprocal relationship between teacher-student relationship and academic achievement. However, so far, this relationship has not been fully explored, such as how teacher-student relationship affects academic achievement and whether academic achievement restricts teacher-student relationship and so on (Košir \& Tement, 2014). For a long time, students have gradually formed and maintained two kinds of social relations in school education, namely, peer relationship and teacher-student relationship. The former is basically in line with the development of academic achievement in later childhood (Ryan et al., 1994), while the latter has a profound impact on the physical and mental development of students (Liao, 2001). Recent educational psychology research has also shown that in school adjustment, teacher-student relationships are often intertwined with students' academic achievement (Furrer \& Skinner, 2003). Overall, the current research focuses on the following three aspects:

\section{The Influence of Teacher-student Relationship on Academic Achievement}

Most studies will first assume that teacher-student relationships can predict academic achievement and thus measure the impact of this relationship on achievement. For example, some scholars have found that teacherstudent conflicts affect children's academic achievement (Hamre \& Pianta, 2001). In fact, these investigations and studies on the role of teacher-student relationship in academic achievement are mostly based on self-determination theory (SDT; Cnnell \& Wellborn, 1991). The theory holds that teacher-student interaction and student participation work together to determine their academic achievement. On this basis, basic needs theory was derived (Ryan et al., 2002). They believe that students have three kinds of psychological needs that are crucial for the participation of teachers, which are autonomy, ability development and relatedness. These needs also affect the quality of students' interpersonal relationships. In particular, the current relationship between students' psychological needs and academic achievement has been clearly documented (Birch \& Ladd, 1997). These studies point out that school climate, teacher-student relationships, and school belonging are closely related to academic outcomes, including positive impact, effort, self-efficacy (Sakiz et al., 2012), engagement, and academic achievement.

(c) 2019 by the authors; licensee Modestum Ltd., UK. This article is an open access article distributed under the terms and conditions of the Creative Commons Attribution License (http://creativecommons.org/licenses/by/4.0/). \XuZhuZhu@163.com $\$ 99040 @ b n u . e d u . c n$ (*Correspondence) 


\section{Contribution of this paper to the literature}

- In terms of previous research, this study comprehensively analyzed the influence of teacher-student relationship and self-efficacy on academic achievement, and focused on the mediating role of self-efficacy. In addition, the participation of large-scale participants helps to improve the accuracy and importance of the research results.

\section{The Influence of Student Achievement on Teacher-student Relationship}

Investigating the relationship between teacher-student relationship and academic achievement often fails to accurately test the impact of academic achievement on teacher-student relationship. Some studies only point out that teachers have a preference for student groups with different characteristics (including academic achievement). These studies have shown that teachers often prefer certain types of students (such as students with good grades), and they themselves are not aware of this unfair treatment (Babad, 1993). To a certain extent, these studies also reflect that students' academic performance does affect teachers' perceptions of them (Aluja et al., 1999).

\section{The Mediating Effect of Student Perceptions}

The relationship between teacher's acceptance of students and academic achievement can have a direct effect, but this does not mean that students can explain themselves (Weinstein et al., 1987). However, teachers' understanding of student achievement can be adjusted by students' perception of teacher behavior (Skinner et al., 2008). In self-determination theory, self is considered to be the intermediary between the adjustment of teacher behavior and student learning behavior and outcome. Teachers' behaviors often do not affect students' motivations, but they do affect how students perceive such behaviors.

Social learning theory has always advocated the combination of behavior and cognition, emphasizing the role of self-factors in regulating behavior. Self-efficacy is an important self-regulation, and its formation factors serve as carriers of efficacy information, and these factors mainly influence academic achievement through the mediating effect of self-efficacy (Bandura, 1997). Some studies have also shown that students' academic self-efficacy will affect their persistence, effort and learning strategies, thus affecting the completion of students' academic tasks and academic achievement (Pajares, 1994). In fact, academic self-efficacy is not only an internal factor that affects students' academic performance, but also plays an important role in regulating other factors that affect academic achievement (Wang, 1999).

From the existing literature, teacher-student relationship and self-efficacy will affect students' academic achievement, and it is likely to regulate teacher-student behavior through self-efficacy. Therefore, it is necessary to combine teacher-student relationship with self-efficacy to analyze their impact on academic achievement. This study, through hierarchical regression analysis, aims to explore whether the influence of teacher-student relationship in mathematical academic achievement and self-efficacy play a mediating role between teacherstudent relationship and academic achievement.

\section{OBJECTS AND METHODS}

\section{Subjects}

In the 104 districts and counties of $\mathrm{Z}$ province in mainland China, two-stage unequal probability sampling was used, that is, the first stage of the school was selected, and the second stage was to select the students in the school. When schools are selected from districts and counties, the schools are stratified according to the nature of the school and the school system. Schools are then selected according to the probabilistic proportional to size (PPS) sampling method in proportion to the number of school pupils. The students are selected according to the systematic sampling method in the second stage. A total of 42,643 eighth grade students from 762 secondary schools were selected. There are 9638 urban students, 12,099 county students and 20,906 rural students. 22,301 are boys, the other 20,342 are girls.

\section{Research Tools}

Teacher-student relationship questionnaire. The questionnaire was compiled by Collaborative Innovation Center of Assessment toward Basic Education Quality. There are 5 items in total, including "I get along well with the math teacher." "The math teacher is very concerned about my physical and mental health." "When I need it, the math teacher is willing to provide extra help" and so on. The questionnaire is a five-point dimension, the higher 
Table 1. Average score and standard deviation of teacher-student relationship, self-efficacy, mathematics achievement $(M \pm S D)$

\begin{tabular}{cccc}
\hline & Mathematics teacher-student relationship & Self-efficacy & Mathematical achievement \\
\hline Male & $3.75 \pm 0.962$ & $3.98 \pm 0.894$ & $317.30 \pm 48.541$ \\
\hline Female & $3.77 \pm 0.836$ & $3.98 \pm 0.747$ & $320.19 \pm 42.806$ \\
\hline Urban & $3.88 \pm 0.907$ & $4.07 \pm 0.821$ & $328.93 \pm 44.326$ \\
\hline County & $3.78 \pm 0.893$ & $4.04 \pm 0.818$ & $325.95 \pm 43.049$ \\
\hline Rural & $3.70 \pm 0.904$ & $3.91 \pm 0.829$ & $309.74 \pm 46.512$ \\
\hline
\end{tabular}

the score, the better the relationship between teachers and students. The alpha coefficient of internal consistency of the questionnaire is 0.928 , the confirmatory factor analysis shows that the questionnaire has a good structural validity $(C F I=0.932, R M S E A=0.05)$.

Self-efficacy questionnaire. The questionnaire was also compiled by Collaborative Innovation Center of Assessment toward Basic Education Quality. It consists of 8 items, including the item "Determining the quantitative relationship between fees and time", "The closest integer of estimated and irrational numbers" and "Using props to design fair games" and so on, using a 5-point scale, from "strongly disagree" to "totally agree." Score from 1 to 5 points respectively. The higher the score, the stronger the self-efficacy of students. The alpha coefficient of internal consistency of the questionnaire in this study was 0.933 , and the confirmatory factor analysis shows that the questionnaire has a good structural validity $(C F I=0.943, R M S E A=0.096)$.

Academic achievement. The mathematics achievement of students is obtained through the quality monitoring of regional mathematics education. The rasch model from item response theory was used to analyze the item to get the mathematics ability value of the student. Then the ability value was converted into a T score (average 300, standard deviation 50). The higher the score, the better the mathematics achievement of students.

\section{Data Collection and Processing}

Each participating student completed the middle school mathematics subject test and questionnaire survey. Both the subject test and the questionnaire survey were answered on the machine-readable card. The survey data was acquired by the network scanning method. Finally, SPSS 22.0 was used for statistical analysis and processing.

\section{RESULTS AND ANALYSIS}

\section{Descriptive Analysis of Teacher-student Relationship, Self-efficacy, and Mathematics Achievement ${ }^{1}$}

Table 1 lists the average and standard deviations of students in different groups in terms of teacher-student relationship, self-efficacy, and mathematics achievement. From the gender point of view, the independent sample t-test found that the relationship between girls and mathematics teachers is better than that of boys, but it has no practical significance $(t=-1.988, p<0.05, d=0.052)$; there is no statistically significant difference in student self-efficacy $(t=-0.271, p>0.05, d=0.009)$; although the mathematics achievement of girls are higher than boys, the effect size of this difference is too small $(t=-6.529, p<0.001, d=0.156)$.

The One-Way ANOVA shows that students from different regions had significant differences in teacher-student relationship, self-efficacy, and mathematics achievement $\left(\mathrm{F}(2,42643)=137.184, p<0.001, \eta^{2} \mathrm{p}=0.006 ; \mathrm{F}(2,42643)=\right.$ 170.655, $\left.p<0.001, \eta^{2} \mathrm{p}=0.008 ; \mathrm{F}(2,42643)=818.366, p<0.001, \eta^{2} \mathrm{p}=0.037\right)$, but the effect size is small. The results of multiple comparison (LSD) also found that the size of the three dependent variables in urban areas was significantly higher than that of counties and towns, and the counties and towns were significantly higher than the rural areas.

\section{Correlation Analysis of Teacher-student Relationship, Self-efficacy and Mathematics Achievement}

Pearson correlation analysis was conducted on teacher-student relationship, self-efficacy and mathematical achievement. The results showed that teacher-student relationship was significantly positively correlated with selfefficacy and mathematical achievement $(r=0.222 \sim 0.496, p<0.01)$. And there was a significant positive correlation between self-efficacy and mathematics achievement $(r=0.341, p<0.01)$. The detailed results are shown in Table 2.

\footnotetext{
${ }^{1} d$ and $\eta^{2}$ p represent the effect size of the t-test and ANOVA, respectively.
} 
Table 2. Correlation coefficient matrix of teacher-student relationship, self-efficacy and math achievement

\begin{tabular}{lccc}
\hline & $\mathbf{1}$ & $\mathbf{2}$ & $\mathbf{3}$ \\
\hline 1.Mathematics teacher-student relationship & 1 & $0.496^{* *}$ & $0.222^{* *}$ \\
\hline 2.Self-efficacy & $0.496^{* *}$ & 1 & $0.341^{* *}$ \\
\hline 3.Mathematical achievement & $0.222^{* *}$ & $0.341^{* *}$ & 1 \\
\hline
\end{tabular}

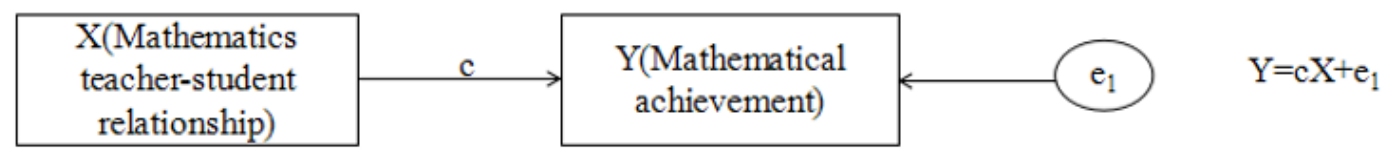

(a)

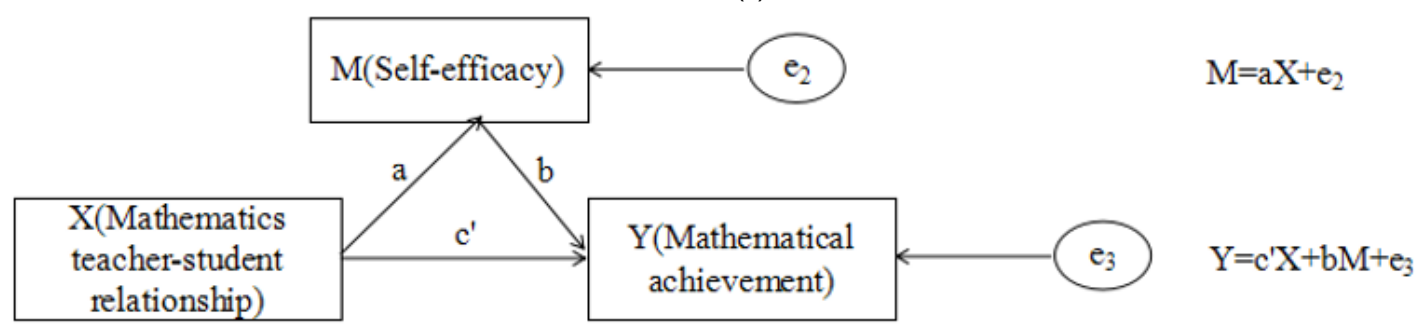

(b)

Figure 1. Schematic diagram of the mediation model

\section{The Mediating Effect of Self-efficacy on Teacher-student Relationship and Mathematics Achievement}

Based on the previous analysis, this study assumes that the teacher-student relationship influences individual mathematics academic achievement through self-efficacy. Using sequential testing procedures (Wen et al., 2004), the possible mediating effects of self-efficacy on teacher-student relationships and mathematics achievement are tested (see Figure 1). Among them, Y represents the coefficient $c$ of the equation (1) as the total effect of the independent variable $X$ on the dependent variable $Y$; the coefficient a of the equation (2) is the effect of the independent variable $X$ on the intermediate variable $M$; the coefficient $b$ of the equation (3) is after controlling the influence of the independent variable $X$, the effect of the mediator variable $M$ on the dependent variable $Y$; the coefficient $c^{\prime}$ is the direct effect of the independent variable $X$ on the dependent variable $Y$ after controlling the influence of the intermediary variable $\mathrm{M} ; \mathrm{e}_{1}$ to $\mathrm{e}_{3}$ are regressions residuals.

This study examines the following models: mathematics teacher-student relationship $(X) \rightarrow$ self-efficacy $(M) \rightarrow$ mathematics academic achievement $(\mathrm{Y})$. Firstly, the regression equations of mathematics achievement and mathematics teacher-student relationship are established. Secondly, the regression equations of self-efficacy and mathematics teacher-student relationship are established. Finally, the regression equations of mathematics academic achievement on teacher-student relationship and self-efficacy are established. The results show that the teacher-student relationship of mathematics can significantly predict self-efficacy $(\beta=0.496, p<0.001)$; the mathematics teacher-student relationship and self-efficacy both have a significant predictive effect on mathematical achievement $(\beta=0.07, p<0.001 ; \beta=0.306, p<0.001)$, indicating that self-efficacy plays a part in mediating the mathematics teacher-student relationship and mathematical achievement. The mediating effect of teacher-student relationship on mathematical achievement is 0.152 , the total effect is 0.222 , so the ratio of mediating effect to total effect is $68 \%$. The results are shown in Table 3 . 
Table 3. Test of the mediating effect

\begin{tabular}{|c|c|c|c|c|c|c|c|c|}
\hline Enter step & Dependent variable & Predictor variable & $\mathbf{R}^{2}$ & $\mathbf{F}$ & B & S.E & $\beta$ & $\mathbf{t}$ \\
\hline \multirow[t]{2}{*}{ First step } & $\begin{array}{c}\text { Mathematical } \\
\text { achievement }\end{array}$ & & 0.049 & 2202.069 & & & & \\
\hline & & $\begin{array}{l}\text { Mathematics teacher-student } \\
\text { relationship }\end{array}$ & & & 11.251 & 0.240 & 0.222 & $46.926^{* *}$ \\
\hline \multirow[t]{2}{*}{ Second step } & Self-efficacy & & 0.246 & 13907.44 & & & & \\
\hline & & $\begin{array}{l}\text { Mathematics teacher-student } \\
\text { relationship }\end{array}$ & & & 0.454 & 0.004 & 0.496 & $\underset{*}{117.930^{*}}$ \\
\hline \multirow[t]{3}{*}{ Third step } & $\begin{array}{c}\text { Mathematical } \\
\text { achievement }\end{array}$ & & 0.120 & 2905.274 & & & & \\
\hline & & $\begin{array}{l}\text { Mathematics teacher-student } \\
\text { relationship }\end{array}$ & & & 3.535 & 0.266 & 0.070 & $13.307^{* *}$ \\
\hline & & Self-efficacy & & & 17.004 & 0.290 & 0.306 & $58.578^{* *}$ \\
\hline
\end{tabular}

\section{DISCUSSIONS}

\section{The Predictive Effect of Teacher-student Relationship on Academic Performance}

The teaching mechanism is a process in which teachers and students participate and cooperate. In this process, a good teacher-student relationship can make students more willing to communicate and interflow with teachers, get more attention and help in learning, get more positive responses in the process of communication, and thus gain better academic achievements.

The data of this study confirms the hypothesis and finds that teacher-student relationship is positively correlated with students' mathematics achievement. Students with higher level of teacher-student relationship are more likely to have higher academic achievement. This study is consistent with the research findings of Birch (1997) and Wang (2002), which once again confirmed the positive role of teacher-student relationship in individual learning, especially in school education.

\section{The Mediating Role of Self-efficacy in Teacher-student Relationship and Academic Achievement}

On the one hand, the teacher-student relationship affects the establishment of individual self-efficacy. In this study, the regression coefficient of the mathematics teacher-student relationship on self-efficacy is 0.496, which indicates that the mathematics teachers' care and attention is conducive to the students to form a healthy learning psychology, thus establishing a higher self-esteem and self-confidence, teacher-student relationship has always influenced the development of positive emotions among students.

On the other hand, self-efficacy also affects academic achievement. Students who are cared and trusted by teachers are more likely to build a strong self-efficacy in their studies. They believe in their ability to overcome learning difficulties and have a lasting motivation for future learning activities. Therefore, these groups are relatively easy to acquire better academic achievement.

\section{Inspiration to Education and Teaching Practice}

This study also has some important inspiration for educational practice. First of all, there are significant differences in mathematical achievement among different groups of students. Especially for rural schools, there is still much space for improvement in education and teaching. Under the background of the integration reform of compulsory education in the urban-rural areas in the mainland China, more support should be given to such schools, leading them to pay attention to the construction of teachers and other aspects, and ultimately improve the quality of education.

In addition, the mechanism of teacher-student relationship affecting academic achievement found in this study shows that teacher-student relationship can improve students' academic performance by affecting their selfefficacy. Therefore, in the process of education and teaching reform, we must strive to build a harmonious teacherstudent relationship, promote emotional communication between them, and shorten the distance between teachers and students. These will not only help students form a high degree of self-efficacy, but also improve their academic achievement. 


\section{CONCLUSIONS}

First, there are certain gender differences and regional differences in the teacher-student relationship. Girls are better than boys, urbans are better than counties and towns, and counties and towns are better than rural areas, but they have no practical significance. There is no gender difference in students' self-efficacy. However, there are certain regional differences in self-efficacy; and there are certain gender differences and regional differences in mathematical achievement. Girls are higher than boys, urbans are higher than counties and towns, and counties and towns are higher than rural areas, though they have no practical significance.

Second, teacher-student relationship can significantly affect mathematical achievement, and has a positive predictive effect; self-efficacy also has a significant positive predictive effect on mathematical achievement, and its impact on mathematical achievement is greater than teacher-student relationship.

Third, for mathematics, self-efficacy plays a part in mediating between teacher-student relationship and academic achievement, and the ratio of mediating effect to total effect is $68 \%$.

\section{REFERENCES}

Aluja-Fabregat, A., Balleste-Almacellas, J., \& Torrubia-Beltri, R. (1999). Self-reported personality and school achievement as predictors of teachers' perceptions of their students. Personality and Individual Differences, 27, 743-753. https:// doi.org/10.1016/S0191-8869(98)00276-1

Babad, E. (1993). Teachers' differential behavior. Educational Psychology Review, 5, 347-376. https://doi.org/10.1007/BF01320223

Bandura, A. (2005). Self-efficacy: the exercise of control. Journal of Cognitive Psychotherapy, 13(2). https:/ / doi.org/10.1891/0889-8391.13.2.158

Birch, S. H., \& Ladd, G. W. (1997). The teacher-child relationship and children's early school adjustment. Journal of School Psychology, 35, 61-79. https:// doi.org/10.1016/S0022-4405(96)00029-5

Connell, J. P., \& Wellborn, J. G. (1991). Competence, autonomy, and relatedness: A motivational analysis of selfsystem processes. In M. R. Gunnar \& L. A. Sroufe (Eds.), Self processes and development: The Minnesota symposia on child development (Vol. 23, pp. 43-78). Hillsdale: Erlbaum.

Furrer, C., \& Skinner, E. (2003). Sense of relatedness as a factor in children's academic engagement and performance. Journal of Educational Psychology, 95, 148-162. https:/ / doi.org/10.1037/0022-0663.95.1.148

Hamre, B. K., \& Pianta, R. C. (2001). Early teacher-child relationships and the trajectory of children's school outcomes through eighth grade. Child Development, 72, 625-638. https:/ / doi.org/10.1111/1467-8624.00301

Košir, K., \& Tement, S. (2014). Teacher-student relationship and academic achievement: a cross-lagged longitudinal study on three different age groups. European Journal of Psychology of Education, 29(3), 409-428. https:/ / doi.org/10.1007/s10212-013-0205-2

Liao, D. (2001). The new development of teacher-student relationship. (Doctoral dissertation).Retrieved from http:/ /cdmd.cnki.com.cn/Article/CDMD-10511-2001007044.htm

Pajares, F., \& Miller, M. D. (1994). Role of self-efficacy and self-concept beliefs in mathematical problem solving: a path analysis. Journal of Educational Psychology, 86(2), 193-203. https:/ / doi.org/10.1037/0022-0663.86.2.193

Ryan, R. M., \& Deci, E. L. (2002). An overview of self-determination theory: An organismic-dialectical perspective. In E. L. Deci \& R. M. Ryan (Eds.), Handbook of self-determination research. Rochester: The University of Rochester Press, 3-33.

Ryan, R. M., Stiller, J. D., \& Lynch, J. H. (1994). Representations of relationships to teachers, parents and friends as predictors of academic motivation and self-esteem. Journal of Early Adolescence, 14, 226-249. https://doi.org/10.1177/027243169401400207

Sakiz, G., Pape, S. J., \& Hoy, A. W. (2012). Does perceived teacher affective support matter for middle school students in mathematics classrooms? Journal of School Psychology, 50(2), 235-255. https:// doi.org/10.1016/j.jsp.2011.10.005

Skinner, E., Furrer, C., Marchand, G., \& Kindermann, T. (2008). Engagement and disaffection in the classroom: Part of a larger motivational dynamic? Journal of Educational Psychology, 100, 765-781. https://doi.org/10.1037/a0012840

Wang, Y., \& Wang, X. (2002). Research on the Relationship between Pupil-student Relationship Characteristics and Student Factors in Pupils. Psychological Development and Education, 17(3), 18-23. https:/ / doi.org/10.3969/j.issn.1001-4918.2002.03.004 
Wang, Z. (1999). Research on the Relationship between Academic Self-efficacy and Academic Achievement of Junior High School Students. Psychological Development and Education, 15(1), 40-44. https:/ / doi.org/10.3969/j.issn.1001-4918.1999.01.009

Weinstein, R. S.,Marshall, H. H., Sharp, L., \& Botkin, M. (1987). Pygmalion and the student: Age and classroom differences in children's awareness of teacher expectations. Child Development, 58, 1079-1093. https:/ / doi.org/10.2307/1130548

Wen Z. L., \& Ye, B. (2014). Mediation Analysis: Method and Model Development. Advances in Psychological Science, 22(5), 731-745. https:/ / doi.org/10.3724/SP.J.1042.2014.00731

\section{APPENDIX}

\section{Questionnaire (English version)}

\section{Teacher-student relationship}

\begin{tabular}{lcccccc}
\hline & $\begin{array}{c}\text { strongly } \\
\text { disagree }\end{array}$ & disagree & uncertain & $\begin{array}{c}\text { agree } \\
\text { totally } \\
\text { agree }\end{array}$ \\
\hline $\begin{array}{l}\text { 1. I get along well with the math teacher. } \\
\text { 2.The math teacher is very concerned about my physical and }\end{array}$ & $(1)$ & $(2)$ & $(3)$ & $(4)$ & $(5)$ \\
mental health. & $(2)$ & $(3)$ & $(4)$ & $(5)$ \\
$\begin{array}{l}\text { 3. When I need it, the math teacher is willing to provide extra } \\
\text { help. }\end{array}$ & $(1)$ & $(2)$ & $(3)$ & $(4)$ & $(5)$ \\
\hline $\begin{array}{l}\text { 4.The math teacher is very happy to listen to me. } \\
\text { 5. The math teacher is fair to me. }\end{array}$ & $(1)$ & $(1)$ & $(2)$ & $(3)$ & $(4)$ & $(5)$ \\
\hline
\end{tabular}

Mathematical self-efficacy

\begin{tabular}{|c|c|c|c|c|c|}
\hline & $\begin{array}{l}\text { strongly } \\
\text { disagree }\end{array}$ & disagree & uncertain & agree & $\begin{array}{l}\text { totally } \\
\text { agree }\end{array}$ \\
\hline $\begin{array}{l}\text { 1. Determine the relationship between the cost (such as } \\
\text { parking fees, telephone charges, etc.) and the amount of time }\end{array}$ & (1) & (2) & (3) & (4) & (5) \\
\hline $\begin{array}{l}\text { 2. What is the estimate of the nearest integer to an irrational } \\
\text { number? }\end{array}$ & (1) & (2) & (3) & (4) & (5) \\
\hline $\begin{array}{l}\text { 3. According to the number of purchased goods and unit } \\
\text { price to compare, calculate which of the two preferential } \\
\text { programs which is more cost-effective }\end{array}$ & (1) & (2) & (3) & (4) & (5) \\
\hline $\begin{array}{l}\text { 4. Use props (such as poker, turntable, etc.) to design a fair } \\
\text { game }\end{array}$ & (1) & (2) & (3) & (4) & (5) \\
\hline 5. Draw conclusions based on known charts & (1) & (2) & (3) & (4) & (5) \\
\hline $\begin{array}{l}\text { 6. Use the ruler to map the method to find the same point } \\
\text { with the non-collinear distance }\end{array}$ & (1) & (2) & (3) & (4) & (5) \\
\hline $\begin{array}{l}\text { 7. Fold the rectangular paper to find out the relationship } \\
\text { between the formed corners }\end{array}$ & (1) & (2) & (3) & (4) & (5) \\
\hline $\begin{array}{l}\text { 8. Explore the angle law of five-pointed star and hexagonal } \\
\text { star }\end{array}$ & (1) & (2) & (3) & (4) & (5) \\
\hline
\end{tabular}

